\title{
MATERNIDADE POLÍTICA: TRAJETÓRIAS DE VIDA, EDUCAÇÃO E LUTAS POR DIREITOS
}

\author{
Gustava Bezerril Cavalcante ${ }^{1}$ \\ Eduardo Ferreira Chagas ${ }^{2}$ \\ Francisca Geny Lustosa ${ }^{3}$
}

\begin{abstract}
Uma mulher saudável assemelha-se muito a um lobo; robusta, plena, com grande força vital, que dá a vida, que tem consciência do seu território, engenhosa, leal, que gosta de perambular ${ }^{4}$.
\end{abstract}

\begin{abstract}
Resumo:
O presente artigo trata da trajetória de quatro mulheres e mães que têm filhos com paralisia cerebral, salvo uma, que ela própria tem $\mathrm{PC}^{5}$. Suas vidas, valores, aprendizagens e experiências mudaram significativamente quando os filhos nasceram. Enfrentando grandes desafios diários e valorizando todas as conquistas, elas tiveram que lutar para garantir direitos, respeito e oportunidades. O desejo de acessar a escola as levou ao encontro de ideias, estratégias de resistência, experiências comuns e a descoberta de força. A Educação foi, inicialmente, o fator agregador e impulsionador que as motivou. A inexistência ou insuficiência da atuação do poder público, a ignorância, os preconceitos, a violência e os estigmas, constituíram-se as principais barreiras presentes nas vidas dessas mulheres e de suas filhas e filhos. A pesquisa, aqui apresentada, tem o objetivo de trazer narrativas que revelam sentimentos, resistência, interesses e desejos. As quatro mulheres e mães participantes da pesquisa, foram entrevistadas no período da pandemia de 2020, de maneira remota e através de videochamada. Para embasar as discussões e articulações teóricas, foram utilizados dentre outros, os/as autores/as: Guacira Louro (2019) refletindo sobre o corpo e identidade; David Le Breton (2013) para pensar o corpo sob uma perspectiva antropológica; Andrew Solomon (2013) com a percepção da relação pais, filhos e a identidade; Elisabeth Badinter (1985) e a reflexão sobre maternidade e amor materno; Maria Tereza Mantoan (2003) e a educação inclusiva; Naomi Wolf (2020) trazendo as construções históricas sobre beleza.
\end{abstract}

${ }^{1}$ Graduada em Ciências Sociais (UFC), especialista em Saúde, Trabalho e Meio Ambiente para o desenvolvimento sustentável (UFC), Mestra em História Social (UFC) e Doutora em Sociologia (UFC), professora da Universidade Estadual do Ceará - UECE. E-mail: gustavabezerril@ hotmail.com

2 Possui graduação em Filosofia pela Universidade Estadual do Ceará (1989), mestrado em Filosofia pela Faculdade de Filosofia e Ciências Humanas (FAFICH) da Universidade Federal de Minas Gerais (1993) e doutorado em Filosofia pela Universität Kassel (2002). É professor efetivo (associado) do Curso de Filosofia e do Programa de Pós-graduação em Filosofia da Universidade Federal do Ceará - UFC e professor colaborador do Programa de Pós-graduação em Educação Brasileira da FACED - UFC. Coordenador do Grupo de Estudos Marxistas - GEM, vinculado ao Eixo Filosofia, Política e Educação, vinculado ao Programa de Pós-graduação em Educação Brasileira da FACED - UFC. Orientador do Programa Jovens Talentos/CNPQ. Atualmente, é PESQUISADOR BOLSISTA DO CNPQ; e dedica suas pesquisas ao estudo da filosofia política, da filosofia de Hegel, do idealismo alemão e de seus críticos, Feuerbach, Marx, Adorno e Habermas. E-mail: ef.chagas@hotmail.com

${ }^{3}$ Professora da Universidade Federal do Ceará (UFC), da Faculdade de Educação (FACED) e do Programa de Pós-Graduação em Educação (PPGE-FACED/UFC). Membro do Observatório Internacional de Inclusão, Interculturalidade e Inovação Pedagógica (OIIIIPe). É Coordenadora do Grupo Pró-Inclusão: Pesquisa e Estudos sobre Educação Inclusiva, Práticas Pedagógicas e Formação de Professores (www.proinclusao.ufc.br). A pesquisadora conta com recursos da Fundação Cearense de Pesquisa FUNCAP - Edital: 03/2019 - Auxílio para Despesas Excepcionais de Pequeno Valor (DEP-016400190.01.00/19 SPU No: 1910584883). ORCID: https://orcid.org/0000-0002-6143-9549. Email: franciscageny@yahoo.com.br

4 ESTÉS, C.P. Mulheres que correm com os lobos: mitos e histórias do arquétipo da mulher selvagem. Tradução Waldéa Barcellos. Rio de Janeiro: Rocco, 1994, p. 26.

5 PC é a abreviação de Paralisia Cerebral. 
Palavras-chave: Maternidade, Mulher, Educação, Paralisia Cerebral.

\section{MATERNITÉ POLITIQUE : TRAJECTOIRES DE VIE, ÉDUCATION ET LUTTES POUR DES DROITS.}

\section{Résumé :}

Cet article traite de la trajectoire de quatre femmes et mères de famille qui ont des enfants atteints de paralysie cérébrale, hormis une seule, elle-même atteinte de $\mathrm{PC}^{6}$. Leur vie, leurs valeurs, leurs apprentissages et leurs expériences ont remarquablement changé à la naissance de leurs enfants. Affrontant de grands défis quotidiens et valorisant toutes les réussites, elles ont dû se battre pour garantir des droits, du respect et des opportunités. Le souhait d'avoir accès à l'école les a amenées à la convergence d' idées, à des stratégies de résistance, à des expériences communes et à retrouver leurs forces. L'Éducation était initialement le facteur de regroupement et le moteur qui les a motivées. L'inexistence ou l'insuffisance de l'action des pouvoirs publics, l'ignorance, les préjugés, la violence et la stigmatisation formaient les principales barrières présentes dans la vie de ces femmes et de leurs filles et fils. La recherche, présentée ici, a pour objectif d'apporter des récits qui révèlent des sentiments, de la résistance, des intérêts et des désirs. Les quatre femmes et mères de famille qui ont participé à la recherche ont été interrogées durant la période de la pandémie de 2020, à distance et par téléconférence. Pour soutenir les discussions et les articulations théoriques, nous avons utilisé les auteur(e)s : Guacira Louro (2019) réfléchissant sur le corps et l'identité; David Le Breton (2013) pour penser le corps dans une perspective anthropologique; Andrew Solomon (2013) avec la perception de la relation entre parents, enfants et identité; Elisabeth Badinter (1985) et la réflexion sur la maternité et l'amour maternel; Maria Tereza Mantoan (2003) et l'éducation inclusive; Naomi Wolf (2020) apportant les constructions historiques sur la beauté.

Mots clés: Maternité, Femmes, Éducation, Paralysie Cérébrale.

\section{Introdução}

(... Eu queria apanhar uma braçada do infinito em luz que a mim se misturava

Eu queria captar o impercebido nos momentos mínimos do espaço

nu e cheio

Eu queria ao menos manter descerradas as cortinas na impossibilidade de tangê-las

${ }^{6} \mathrm{PC}$ est l'abréviation pour Paralysie Cérébrale.

\begin{tabular}{|c|c|c|c|c|}
\hline Qovista Dialectus & Ano 9 & n. 20 & Outubro - Novembro 2020 & p. $209-236$ \\
\hline
\end{tabular}


O presente artigo apresenta e reflete sobre as narrativas de quatro mulheres que possuem o desafio comum, de reelaboração diária da maternidade. Esses processos de construção são tencionados pela não aceitação social de suas filhas e seus filhos, devido a condição da paralisia cerebral destes. Os olhares das quatro mães, voltados para suas vivências da maternidade, experiências de vida, memórias, sentimentos e reflexões, inspiraram as análises aqui escritas.

A escolha do tema se deu pelo fato de minha aproximação e vivência com as mesmas questões, pois também possuo um filho com paralisia cerebral. A escolha das quatro mulheres participantes da pesquisa foi feita, a partir de indicações de pessoas envolvidas com as lutas por inclusão escolar em Fortaleza ${ }^{7}$. Todas as mães escolhidas, tem histórias de luta por inclusão na escola e na sociedade.

Conhecer essas mulheres impactou de modo especial, na possibilidade de aprender a partir de suas ricas experiências, pois foram guiadas pela luta em função do reconhecimento de suas filhas e filhos e de seus direitos sociais, inclusive, constituíramse enquanto pioneiras em Fortaleza.

Elas são mães de crianças e jovens com deficiência, mulheres e trabalhadoras, que acreditaram no potencial coletivo de uma rede de apoio, na força das trocas e no compartilhamento de seus conhecimentos. Mulheres que se uniram, em torno da maternidade de "filhos com deficiência", ao que emerge como marca de uma maternidade política!

Devo ainda dizer que, três situações uniram as participantes da pesquisa que partilharam, generosamente, suas visões de mundo para a elaboração deste texto. A primeira diz respeito à vontade comum de buscarem alternativas de aprendizagem e socialização, para suas filhas e filhos que não foram aceitos nas escolas públicas do bairro em que moravam. A segunda, foi o despertar para a percepção da existência de direitos das pessoas com deficiência, através do conhecimento da Declaração de Salamanca ${ }^{8}$. E

\footnotetext{
${ }^{7}$ Francisca Geny Lustosa, professora da Faculdade de Educação da UFC e Davi Souza, estudante do curso de Pedagogia da UECE e membro do CAMPE - GRUPO DE APOIO A MÃES E PAIS DE PORTADORES DE EFICIÊNCIA.

${ }^{8}$ A Declaração de Salamanca é um importante documento das Nações Unidas, elaborado em junho de 1994 por representantes de 88 países e 25 organizações internacionais. Estes se uniram com o objetivo maior, de assegurar que a educação de pessoas com deficiência fosse parte integrante do sistema educacional, de maneira completa, plena, lúdica e satisfatória.
} 
a terceira, a disposição para a mobilização e transformação de maneiras de pensar e agir em relação a suas filhas e filhos.

Vale destacar que, mesmo que a condição de mãe, seja um importante elemento de reflexão para a discussão aqui posta, esta não foi trabalhado de maneira exclusiva. A a condição de ser mulher e os desafios da luta por educação, interfacearam as análises deste texto.

Optou-se então por partir inicialmente, não de conceitos médicos sobre a paralisia cerebral, e sim, da relação corpo, deficiência e cultura, expressa por David Le Breton:

\footnotetext{
O homem é moralmente reduzido apenas ao estado de seu corpo percebido como um absoluto; é deduzido, de certa forma, pela maneira como aparece aos olhos dos outros. A anatomia tem aqui valor de destino. Fala-se, aliás, de "deficiente", como se fosse da natureza da pessoa "ser um deficiente" mais do que "ter" uma deficiência. (LE BRETON, 2013, p. 87).
}

O autor nos chama a atenção para o fato de que a deficiência é apenas um aspecto da pessoa, e não, a sua essência. Somos todos plurais. Temos muitas faces, potencialidades e dificuldades. Jamais seremos uma "coisa" só, apesar de sermos únicos. Quando a pessoa com deficiência compreende isso, e também sua rede de apoio, a batalha pelo reconhecimento e aceitação começa a ter outra tecitura - a da aceitação, criatividade e construção de uma autonomia.

\section{Quem são elas?}

Eu sou aquela mulher a quem o tempo muito ensinou.

Ensinou a amar a vida e não desistir da luta, recomeçar na derrota, renunciar a palavras e pensamentos negativos. Acreditar nos valores humanos e ser otimista.

Cora Coralina

Diante do que foi dito, conhecer um pouco de cada uma das quatro mulheres entrevistadas é um importante passo para facilitar a compreensão dos leitores interessados

\begin{tabular}{|c|c|c|c|c|}
\hline Qovista Dialectus & Ano 9 & n. 20 & Outubro - Novembro 2020 & p. $209-236$ \\
\hline
\end{tabular}


pelo tema. Cada uma das mães, evidentemente, possui particularidades na forma de ver o mundo, mesmo que em vários momentos vivenciem circunstâncias comuns negativas e positivas.

Vale dizer que foram usados os nomes verdadeiros para identificar as narrativas de todas as mulheres entrevistadas. Outro aspecto a ser destacado é que cada uma das participantes possui uma questão mais significativa que marca a experiência da maternidade. Durante a realização das entrevistas e também nos momentos de transcrição, foram escolhidos os trechos de suas falas que se aproximavam dessa perspectiva central e mais motivadora para cada uma delas.

A primeira entrevistada foi Keila Leite Chaves, uma mulher de 52 anos, mãe do David, um rapaz de 25 anos. Se autodeclara parda, é casada e afirma ser uma dona de casa. Tem nível de escolaridade, superior incompleto. Mora no bairro Itaperi. É uma liderança política de muita expressão que atuou no início dos anos 2000, em Fortaleza, lutando por uma educação inclusiva. Na verdade, atua até hoje. Participou de eventos nacionais e internacionais representando o Ceará nas discussões sobre os direitos da pessoa com deficiência e é sócia fundadora do CAMPE $^{9}$. A entrevista foi muito marcada por sua experiência militante e capacidade mobilizadora pela causa da inclusão, em especial.

A expressividade da luta de Keila, materializou-se na formação de uma instituição na qual se projetou como sócia fundadora e primeira presidenta - o Centro de Apoio à Mães de Portadores de Eficiência (CAMPE), em 2003, cuja missão é promover a defesa dos direitos e acessibilidade, ao exercício da cidadania de pessoas com deficiência, no Estado do Ceará.

A segunda entrevistada foi Verônica Rodrigues Paiva, mulher de 54 anos. Se autodeclara parda. É casada atualmente, mas não com o pai de Leandro, seu filho de 34 anos, que tem paralisia cerebral. Possui nível superior incompleto, pois cursou

\footnotetext{
${ }^{9}$ O Centro de Apoio a Mães de Portadores de Eficiência - CAMPE é uma associação civil, sem fins lucrativos, fundada em 2003 e tem como missão a defesa social de direitos fundamentais da pessoa com deficiência. O objetivo desta instituição é contribuir de forma direta para o processo de inclusão, tendo como foco principal a família e a pessoa com deficiência. A entidade se configura exercendo um papel fundamental na discussão do Plano Municipal de Fortaleza, pautando a EDUCAÇÃO INCLUSIVA, que, em decorrência disso, tornou-se referência na cidade e no estado acerca da temática. Rua - Edgar de Arruda, 480 -Jockey Club-CEP: 60510 - 350 Fortaleza - CE Fone(Fax): 85 3496.5877/8119-7182 Email: campe_2003@hotmail.com centrodeapoioamaes@yahoo.com.br. Informa ções disponíveis em < http://campefortaleza.blogspot.com/>. Acessado em 17/02/2021.
}

\begin{tabular}{|c|c|c|c|c|}
\hline Qovista Dialectus & Ano 9 & n. 20 & Outubro - Novembro 2020 & p. $209-236$ \\
\hline
\end{tabular}


administração pela UNIPE ${ }^{10}$. Afirma ser dona de casa. Tem ao todo três filhos. Mora no bairro Siqueira. Participou das lutas por inclusão em Fortaleza, juntamente com Keila e outras mães. Sua fala é profundamente marcada pelo desejo de ser uma mulher mais livre. E pelo medo do futuro.

A terceira entrevistada foi Francisca Edilene Rodrigues de Lima, mulher de 31 anos. Edilene se autodeclara parda e tem paralisia cerebral. Mora no bairro Bom Sucesso, é casada e mãe de Izaque que tem 10 anos. Izaque foi diagnosticado com TDAH -Transtorno de Déficit de Atenção com Hiperatividade. Edilene possui uma fala muito voltada para a afirmação de uma independência, pois conseguiu organizar sua vida com uma rotina que inclui os cuidados com o filho, a casa e o autocuidado. Contou muito com a ajuda do pai de Izaque. Além disso, ministra palestras sobre paralisia cerebral. Edilene preserva as amizades e sempre tem um tempo para seu lazer. Essa é uma peculiaridade muito importante do seu perfil.

A quarta entrevistada foi Aldeneide Teixeira de Lima - mais conhecida como Neide. Tem 47 anos, é casada, se autodeclara parda e possui dois filhos, dentre eles Débora, de 25 anos, que tem paralisia cerebral. É formada em Pedagogia pela UVA Universidade do Vale do Acaraú. Mora no bairro Jóquei Clube. Tem sua fala fundamentada na militância e nos processos de tratamento terapêutico da filha. Além disso, expressa uma grande preocupação com os processos de formação de mães, sobre a paralisia cerebral e a maternidade.

Vale lembrar que, as entrevistas foram realizadas em 2020, através de video chamada, devido ao período de pandemia ocasionada pela COVID-19 e o isolamento social vivenciado neste período. Mesmo com esse difícil contexto, as mulheres contactadas participaram com muita boa vontade e alegria dos momentos de entrevista.

\section{O que as uniu?}

(...) As coisas acontecidas, mesmo longe, ficam perto para sempre e em muitas vidas

Cecília Meireles

${ }^{10}$ Centro Universitário de João Pessoa.

\begin{tabular}{|l|l|l|l|l|}
\hline Q Rovista Qialectus & Ano 9 & n. 20 & Outubro - Novembro 2020 & p. 209-236 \\
\hline
\end{tabular}


Todas as mães entrevistadas iniciaram suas trajetórias de mobilização, interessadas por de acessar a escola pública e denunciar a invisibilidade, a discriminação e o isolamento vividos diariamente por suas filhas e filhos. Uma grande luta então se deu, a partir da união de mães que se encontravam desejosas por transformações na sociedade cearense.

Sobre o desejo de reconhecimento, Guacira Louro contribui:

O reconhecimento do "outro", daquele ou daquela que não compartilha dos atributos que possuímos, é feito a partir do lugar social que ocupamos. De modo mais amplo, as sociedades realizam esses processos e, então, constroem os contornos demarcadores das fronteiras entre aqueles que representam a norma (que estão em consonância com seus padrões culturais) e aqueles que ficam fora dela, às margens. (LOURO, 2019, p. 17-18).

Daí uma história de muitos desafios foi iniciada. Uma história “escrita”, como nos diz Guacira Louro, por pessoas que não representavam a norma, e que se recusaram a continuar às margens, marcando definitivamente, as lutas cearenses por inclusão e defesa de direitos da pessoa com deficiência.

A formação do CAMPE - GRUPO DE APOIO A MÃES E PAIS DE PORTADORES DE EFICIÊNCIA, já traz, no seu nome e concepção, a ideia de mudança de perspectiva, pois a deficiência é tratada como "eficiência".

\footnotetext{
CAMPE esse é um grupo de mães que se conheceram quando estavam em busca por educação dos filhos. E se conheceu numa instituição especial. A gente estava dentro e se deparou com várias realidades e também posso dizer que com algumas coisas que não eram lícitas. E a gente começou a se reunir e a procurar e a fazer um conselho de mães. Então, desse conselho surgiu a ideia da gente tá fazendo a nossa própria casa onde a gente ficasse com os nossos filhos, porque a gente tinha receio e a impressão que a gente tinha era que ia acabar. E a gente não queria que os filhos voltassem para dentro do quarto, porque a situação de todos que estavam lá era de isolamento mesmo. Eles não conheciam nada, não saíam de casa. A não ser a rede. $\mathrm{O}$ acesso que tinham ao mundo era pela televisão. (Keila, 52 anos / Junho, 2020).
}

Keila explica, em sua narrativa, como mães que não se conformaram em ter as matrículas de seus filhos negadas em escolas públicas, se uniram para buscar alternativas em outra instituição. Trata também de um importante dado, pois a negação causada pelos preconceitos da sociedade, em relação a deficiência, naturalizou uma lamentável situação de isolamento social, em que filhos e familiares foram impedidos de viverem e se desenvolverem como qualquer outra pessoa que não possui deficiência. Essa

\begin{tabular}{|c|c|c|c|c|}
\hline Qevista Dialectus & Ano 9 & n. 20 & Outubro - Novembro 2020 & p. $209-236$ \\
\hline
\end{tabular}


situação ainda ocorre nos dias de hoje, e funciona sob uma lógica restritiva e implica em uma real penalização, fruto da não adequação no suposto grupo dos "normais".

Sobre a concepção de inclusão escolar, Maria Tereza Mantoan contribui:

\begin{abstract}
Os sistemas escolares também estão montados a partir de um pensamento que recorta a realidade, que permite dividir os alunos em normais e deficientes, as modalidades de ensino em regular e especial, os professores em especialistas nesta e naquela manifestação das diferenças. A lógica dessa organização é marcada por uma visão determinista, mecanicista, formalista, reducionista, própria do pensamento científico moderno, que ignora o subjetivo, o afetivo, o criador, sem os quais não conseguimos romper com o velho modelo escolar para produzir a reviravolta que a inclusão impõe. (MANTOAN, 2003, p. 13).
\end{abstract}

A autora critica a escola formada sob moldes conservadores e a lógica binária, que aparta alunos e professores, alimentando, por conseguinte, concepções discriminatórias e excludentes. A perspectiva da educação inclusiva, ao contrário, parte de toda uma argumentação filosófica totalmente oposta a esta, e reivindica uma escola que deve reconhecer e trabalhar as potencialidades plurais de todos os indivíduos, compreendendo o conhecimento como algo essencialmente construído de maneira particular, criativa e lúdica. Para tanto, necessitaremos de uma reviravolta na educação, inspirada em uma ambiência solidária, participativa e acolhedora. (MANTOAN, 2003).

Outro elemento, em comum, foi o curioso contato das mulheres paraticipantes da pesquisa com a Declaração de Salamanca, que provocou um significativo processo de "tomada de consciência" sobre a abrangência dos direitos de suas filhas e filhos:

Na verdade, uma professora me deu a Declaração de Salamanca (Nações Unidas, 1994). Ela disse: - Quando eu li, eu não acreditei no que eu tava lendo! Eu cheguei para ela e perguntei:- Isso aqui vale no Brasil? Quer dizer que o meu filho tem direito a escola que tá ali do outro lado? Ela foi e disse:- Tem. Quer dizer que bastou eu não saber, pra ser negado?Aí eu fiquei indignada de ter sido enganada. E aí nós fomos atrás. E fomos fazer uma manifestação no terminal. Vamos divulgar, porque isso aqui ninguém sabe! A gente pensava assim. E lá no terminal veio uma reportagem. Chamaram. Não sei quem foi. Aí quando foi no outro dia chegou na instituição o CEDECA - Centro de Defesa da Criança e do Adolescente. Eles viram a reportagem que mães estavam no terminal pedindo por escola pra pessoas com deficiência. Desde então, eles são nossos parceiros. Hoje a gente faz parte da comissão dos direitos à educação, do comitê Ceará da campanha nacional do direito a educação. $\mathrm{E}$ tudo devido a essa parceria com o CEDECA, porque foram pessoas que ajudaram, empoderaram e nos fortaleceram. A gente ficou sabendo dos direitos, mas a gente não sabia até que ponto era direito mesmo. Como lutar e ir atrás. Foi uma parceria muito importante pro crescimento da gente... a gente queria mostrar o outro lado dos nossos filhos. A gente queria mostrar que eles podiam viver em comunidade. (Keila, 52 anos/ Junho, 2020).

\begin{tabular}{|c|c|c|c|c|}
\hline Qevista Dialectus & Ano 9 & n. 20 & Outubro - Novembro 2020 & p. $209-236$ \\
\hline
\end{tabular}


Keila chega a uma questão central - a negação da possibilidade de "vida em comunidade". Em pleno século XXI, as escolas, na sua maioria, ainda são extremamente conservadoras e excludentes e não conseguem assimilar a necessidade e o potencial do respeito às diferenças. Consequentemente, esse fato aflige as famílias. Daí as mobilizações e articulações com importantes instituições parceiras das causas inclusivas, como é o caso do CEDECA ${ }^{11}$. Além de cuidados a mais com os filhos, as mães precisaram lutar, como podiam, para ter o direito à escola garantido.

O CAMPE foi uma forma de resposta a ignorância, na época às pessoas em relação ao preconceito mesmo com as crianças com deficiência. A gente, naquela época, não tinha opção de tratamento, as mães não tinham conhecimento dos direitos das nossas crianças. Então assim, de uma forma e de outra a gente foi tendo conhecimento dos direitos. Eu me lembro que a gente começou a ver a lei da Salamanca. (Verônica, 54 anos / Junho, 2020).

Verônica traz, em sua narrativa, a existência de um estigma de incapacidade (GOFFMAN, 1988), "colado" à pessoa com deficiência, fato que maltrata profundamente a todos os envolvidos com a situação e limita, uma mudança de mentalidade e de atitudes reais, inclusive, já garantidas pelas leis brasileiras. Novamente, a Lei de Salamanca foi citada como um importante marco que impulsionou as mobilizações pelos direitos das pessoas com deficiências.

\begin{abstract}
$\mathrm{Na}$ época, a gente via o preconceito não só com as nossas crianças, mas com as outras também. Entendeu? Quando a gente foi pra dentro da escola foi que a gente viu que realmente faltava muita coisa pra escola realmente funcionar de verdade, no geral. Não só pras nossas crianças, mas para todas as crianças. Aí a gente começou a querer conhecer as políticas públicas da educação. Ia pra secretaria de educação do município para a gente participar das reuniões. Ia conhecer os movimentos que existiam na cidade. A gente ia pra dentro dos postos de saúde, se envolvia com os conselhos para gente ter um argumento pra gente cobrar os direitos mesmo de verdade, certo. (Verônica, 54 anos / Junho, 2020).
\end{abstract}

A observação de Verônica, revela o quanto a escola pode acabar sendo um espaço pouco acolhedor para todos, e não exclusivamente para as crianças e adolescentes

11 O Centro de Defesa da Criança e do Adolescente - CEDECA Ceará é uma organização não governamental fundada após a promulgação do Estatuto da Criança e do Adolescente - ECA, que tem como missão "defender os direitos de crianças e adolescentes, especialmente quando violados pela ação ou omissão do Poder Público, visando o exercício integral e universal dos direitos humanos". A parceria com a instituição foi apontada pelas participantes da pesquisa como fundamental para as conquistas realizadas. Ver site: http://cedecaceara.org.br/site/index.php/quem-somos/.

\begin{tabular}{|l|l|l|l|l|}
\hline Qenista Dialectus & Ano 9 & n. 20 & Outubro - Novembro 2020 & p. 209-236 \\
\hline
\end{tabular}


com deficiências. Muitos não se encaixam nos padrões estéticos e intelectuais exigidos. Muitos são os que sofrem os horrores da inadequação social. A escola, não raras vezes, naturaliza esse quadro cruel. Os preconceitos, estigmas e rejeições são extremamente prejudiciais para a formação completa das alunas e dos alunos, pois a convivência com as diferenças é essencialmente, impulsionadora de mudanças e de processos de aprendizagem nas mais diversas dimensões humanas. Na verdade, a diferença é a característica que melhor se adequa ao que compreendemos como humano. A escola que é um reflexo da sociedade, considera as diferenças, quando muito, enquanto algo que precisa ser respeitado, mas sabemos que é mais do que isso. As diferenças constituem o real sentido de troca e de aprendizagem. O ser humano aprende com o outro, com o diferente, com aquele que the faz avançar e transcender o que ele mesmo já é.

\begin{abstract}
No começo, a gente entrou na comissão do direito a educação porque na verdade em 2003 a gente fez essas atividades e em 2004 a gente tava fazendo justamente companhas para a matrícula na escola. A gente fez uma reunião com as mães, aí o CEDECA veio e as mães em grupo, cada uma colocando a sua realidade depois veio a equipe de transição da prefeitura pra vê quais as demandas daquelas mães. Tivemos esse momento lá no CAMPE. E aí tivemos um momento de matrícula onde a gente chamou a comissão, o ministério público, a imprensa, pra escola Professor José Sobreira de Amorim. Nós levamos todos os nossos meninos para serem matriculados. (Keila, 52 anos /Junho, 2020).
\end{abstract}

As lutas passaram a ser as grandes motivações das vidas das mulheres e mães entrevistadas. E a repercussão das mobilizações acabaram levando as crianças a serem matriculadas na escola Professor José Sobreira de Amorim. Infelizmente, matricular apenas, não garantiu a mudança de mentalidade, tão desejada e necessária. Com a inserção das mães na escola, as demandas só aumentaram e a percepção de que as lutas não teriam fim, também.

Sobre os efeitos positivos da união dessas mães, Andrew Solomon ressalta:

Participar de um grupo parece sempre fazer sentido, o poder redentor de intimidades nascidas da luta é imenso. Em nossa era da internet, quando cada problema ou deficiência tem uma comunidade ligada a ele, pais de pessoas com qualquer problema determinado também podem encontrar sua comunidade horizontal. (SOLOMON, 2013, p. 40).

Verônica relata a gravidade dos problemas da escola escolhida para receber as crianças com deficiência. As mudanças eram urgentes para todos, e a meta maior era transformar mentalidades e mentes preconceituosas. As mães do CAMPE sabiam que

\begin{tabular}{|l|l|l|l|l|}
\hline Gevista Dialectus & Ano 9 & n. 20 & Outubro - Novembro 2020 & p. 209-236 \\
\hline
\end{tabular}


um bom caminho seria o das políticas públicas estaduais. Sendo assim, elas foram ampliando o raio de atuação para conscientizar sobre a problemática da deficiência e necessidade urgente de inclusão.

\begin{abstract}
$\mathrm{Na}$ verdade, a gente queria era incluir mesmo, e não só na escola. A gente passou um tempo sendo chamada para as reuniões de sensibilizações de professores pela prefeitura e reuniões com a comissão. Aí passamos a participar da comissão de defesa do direito a educação na época. A gente, todos os anos, acompanhava o período de matrícula. (Keila, 52 anos / Junho, 2020).
\end{abstract}

Keila fala sobre as atividades das mães que, com o tempo, se comprometeram com processos de formação de professores e acompanhamento de matrículas em diversas escolas de Fortaleza. Contribuíam sempre com relatos de vida, desconstruindo preconceitos e ressignificando a deficiência, mostrando também, que essas crianças e adolescentes tão discriminados, possuem a capacidade de inserção em atividades e rotinas diversificadas.

\begin{abstract}
A gente se reúne todo o mês, justamente para discutir em relação as políticas. Hoje a gente faz parte do Fórum DCA, do comitê Ceará da Campanha, tem atividades em relação a campanha, tem o FUNDEB (Fundo Nacional de Desenvolvimento da Educação Básica) aí que tá pra ser votado. A gente participa dessas articulações. Políticas públicas, a própria educação especial na perspectiva de educação inclusiva, teve muito da nossa contribuição. Nas conferências a gente participou - a CONAE (Conferência Nacional de Educação), a CONEB (Conferência Nacional da Educação Básica). Foi luta feia! Da gente terminar exausta, chorando! De ver o que a gente tá vendo hoje. Hoje a gente está assistindo e não quer acreditar que existam pessoas que queiram a discriminação. A gente não quer acreditar que isso existe! (Keila, 52 anos/ Junho, 2020).
\end{abstract}

Agendas intensas de mobilização passaram a fazer parte da vida de Keila, sempre com o objetivo de divulgar a importância da efetivação da educação inclusiva e dos direitos das pessoas com deficiência. A entrevistada supracitada, chama a atenção ainda, para os retrocessos que vêm acontecendo no Brasil, devido ao fortalecimento da bancada conservadora e reacionária do governo Bolsonaro, visto que esta não aceita a perspectiva de uma escola inclusiva e defende a volta das escolas especiais, onde alunas e alunos com deficiência, não devem interagir com os ditos "normais". Esse foi o mais recente ataque às conquistas históricas pela obrigatoriedade e aceitação das matrículas das alunas e alunos com deficiência nas escolas públicas e privadas no Brasil. Enquanto ainda estavam sendo travadas grandes batalhas pela qualidade do ensino e pela 
perspectiva inclusiva, a bancada bolsonarista segregacionista e racionária, argumentava que existem "lugares" específicos para cada "tipo de pessoa". Uma lástima e um tiro nos carações de mães que lutam pelo direiro de inserção em escolas não apenas socializando, mas aprendendo efetivamente e somando com tadas e todos da comunidade escolar.

Keila e outras mães lutam para que o Estado, que se guia pela máxima igualdade de direitos, garantida na Constituição brasileira de 1988, seja realmente efetivada e que, suas filhas e filhos, acessem uma escola pública de qualidade, assim como qualquer outra criança e adolescente do país. Sobre essa questão da relação Estado e justiça, Eduardo Chagas nos diz:

O Estado compromete a justiça. Essa é uma justiça política e não uma justiça social e uma justiça injusta, meramente política, pois parte da ideia de que todos somos iguais, mas o Estado oculta uma Educação universal. Oculta uma justiça no mundo material, concreto. (CHAGAS, live 23/11/2020) ${ }^{12}$.

O Capacitismo ${ }^{13}$ tão combatido pelas mães, pelas organizações que almejam a garantia dos direitos humanos e pelos movimentos sociais da educação, é uma ameaça real à perspectiva da escola inclusiva. Esse mesmo capacitismo está presente, fortemente, na lógica dos que não querem as pessoas com deficiência nas escolas regulares brasileiras.

$\mathrm{Na}$ escolas públicas ou particulares, ainda são raras as iniciativas pegagógicas que obtêm sucesso com as pessoas com deficiência, pois a intolerância e a ignorância em relação a própria ideia de educação, estão longe de chegar ao entendimento desta problemática. Além disso, ainda há muito desconhecimento sobre as especificidades das deficiências, não somente em relação as dificuldades existentes, mas principalmente, a respeito dos potenciais possíveis de cada uma delas. Na grande maioria das vezes, as pessoas com deficiências são percebidas unicamente pelo que não conseguem fazer e suas habilidades nem seguer são reconhecidas e muito menos, exploradas.

\section{A maternidade}

${ }^{12}$ Ver live do Grupo de Estudo Marxista / GEM UFC - coordenado pelo professor Eduardo Chagas da Universidade Federal do Ceará com o tema: Justiça, Educação e Realidade Brasileira. https://www.youtube.com/watch?v=4DAfe0vVUQI .

${ }_{13} \mathrm{O}$ capacitismo é a discriminação de pessoas com deficiência. A lógica capacitista considera os corpos padrões como sendo os únicos a serem aceitos, daí desenvolvem rejeição à aqueles que têm algum tipo de deficiência.

\begin{tabular}{|l|l|l|l|l|}
\hline Q Rovista Dialectus & Ano 9 & n. 20 & Outubro - Novembro 2020 & p. 209-236 \\
\hline
\end{tabular}


Mães não têm tempo para o ensaio: estreiam a peça no susto.

Adélia Prado

Refletir sobre maternidade implica em considerar diversas perspectivas, sentimentos e teorias, mas uma delas é central - ela é considerada por muitos, como um ato instintivo, visto que faz parte da natureza da mulher gerar e parir. No caso aqui então, o amor materno, também seria instintivo. E essa visão acaba por ser atrelada a outra, que é a de parir um filho dito "perfeito". Sobre o assunto, Elisabeth Badinter esclarece:

\begin{abstract}
O amor materno foi por tanto tempo concebido em termos de instinto que acreditamos facilmente que tal comportamento seja parte da natureza da mulher, seja qual for o tempo ou o meio que a cercam. Aos nossos olhos, toda mulher ao se tornar mãe, encontra em si mesma todas as respostas à sua nova condição. Como se uma atividade pré-formada, automática e necessária, esperasse apenas a ocasião de se exercer. Sendo a procriação natural, imaginamos que ao fenômeno biológico e fisiológico da gravidez deva corresponder determinada atitude maternal. (BADINTER, 1985, p. 20).
\end{abstract}

Ser mãe de uma pessoa com deficiência é algo que leva as mulheres a enfrentar desafios diários. Em relação aos desafios psicológicos, as mães precisam primeiro passar por profundo processo de aceitação das deficiências de suas filhas e filhos, para depois, começaram a conseguir encarar as barreiras sociais e culturais existentes em seus cotidianos. Esse processo de aceitação interno pode durar anos para algumas, pode ser mais rápido para outras e também pode nunca acontecer para uma parte das mulheres. Sobre esse imaginário do filho ideal construído culturalmente, Andrew Solomon esclarece:

O fato de ter filhos excepcionais exagera as tendências dos pais: aqueles que seriam maus pais se tornam pais péssimos, mas aqueles que seriam bons pais, muitas vezes, se tornam extraordinários. Assumo uma posição antitolstoiana e digo que as famílias infelizes que rejeitam seus filhos têm muito em comum, ao passo que as felizes que se esforçam para aceitá-los são felizes de uma infinidade de maneiras. (SOLOMON, 2013, p.17). ${ }^{14}$

\footnotetext{
${ }^{14}$ Esta citação possui uma nota que esclarece a argumentação do autor quanto a sua posição antitolstoiana. Em nota de número 9, há o seguinte destaque: Da frase de abertura do romance Anna Kariênina, de Liev Tolstói: “ Todas as famílias felizes se parecem; cada família infeliz é infeliz à sua maneira”. O autor inverte a ideia, à luz de suas experiências.
}

\begin{tabular}{|c|c|c|c|c|}
\hline Qevista Dialectus & Ano 9 & n. 20 & Outubro - Novembro 2020 & p. $209-236$ \\
\hline
\end{tabular}


Outro desafio que marca as peculiaridades das mães de pessoas com paralisia cerebral, diz respeito aos cuidados com as filhas e filhos que perdurarão por muito tempo, ou até pela vida toda. No caso das mães que não possuem condições financeiras para contar com a ajuda de profissionais, que auxiliem na rotina, elas praticamente sozinhas cuidam da higiene pessoal, alimentação, deslocamento em casa e fora de casa, lazer, acompanhamento da educação, inserção em grupos sociais e outros. Muitas vezes, possuem também mais filhos. Trabalham literalmente dia e noite, a fim de conseguir o sustento de suas casas. E se desdobram para garantir a saúde física e mental de suas filhas e filhos. Se para todas as mulheres, a carga cultural do trabalho fora de casa e dentro de casa é muito maior do que, a dos homens, não nos custa imaginar o quanto para essas mães, as responsabilidades ainda são maiores, visto que a autonomia de suas filhas e filhos é muito limitada. E, a bem da verdade, a autonomia delas próprias também, pois não raras vezes, dependem economicamente de seus maridos para o sustento da casa.

Em relação ao trabalho diário de mulheres, não reconhecido e doméstico, Naomi Wolf coloca em questão a intensidade da carga diária e semanal de trabalho, de uma mulher.

\footnotetext{
As mulheres trabalham mais, sejam elas orientais ou ocidentais; sejam donas de casa ou tenham empregos remunerados. Uma mulher paquistanesa gasta 63 horas por semana, apenas nas tarefas domésticas, enquanto uma dona de casa ocidental, apesar dos aparelhos modernos, trabalha somente seis horas a menos.(WOLF, 2020, p. 430).
}

O problema é muito complexo, pois efetivamente, as mães de pessoas com deficiência deveriam ter muito mais apoio do poder público, dos familiares e de instituições não governamentais.

Por outro lado, são essas mulheres que mais aprendem com esta convivência tão próxima com suas filhas e filhos. Aprendem, por exemplo, a ter outro olhar em relação as dificuldades da vida, a valorizar cada conquista e a ampliarem a suas próprias possibilidades de comunicação, já que exercitam constantemente a empatia, a sensibilidade e o amor.

Certamente, que nem todas as mães conseguem vencer os obstáculos postos, pois muitas vezes, não encontram apoio, como já foi dito, às vezes até dentro da própria

\begin{tabular}{|l|l|l|l|l|}
\hline Gevista Dialectus & Ano 9 & n. 20 & Outubro - Novembro 2020 & p. 209-236 \\
\hline
\end{tabular}


família. Alguns casos são desesperadores e essas mulheres caem em profunda depressão, ou, até mesmo, tentam suicídio.

Então assim, o nascimento dele, todo mundo diz que tem o luto e a luta! Eu não tive o luto porque o meu medo era de perdê-lo. E assim, quando eu soube que era só uma deficiência eu disse assim - ah, muito bem, vou cuidar dele, tiro de letra! Porque o meu medo era de perder novamente. Eu não sabia se ia ter estrutura pra suportar de novo uma perda. (Keila, 52 anos / Junho 2020).

Keila, em um momento de sua entrevista, relata a perda de uma filha e quando David nasceu, o que ela mais queria era não perdê-lo. E assim foi. Com o nascimento de David, muitos ganharam além dela própria, pois Keila se tornou uma defensora da inclusão das pessoas com deficiência, não somente nas escolas, mas também em todas as instâncias da vida em sociedade ${ }^{15}$. Ela diz que não viveu o luto inicial, tão comumente relatado por muitas mães de pessoas com deficiência, quando recebem "a notícia" ou o primeiro diagnóstico, geralmente revelado por um médico sem a menor sensibilidade ou preparo para tal coisa. E a luta foi realmente a marca da sua relação com David.

Acho que de muita cumplicidade. Eu não sei nem explicar assim. Agora assim ele me passa muito aprendizado, sabe? Eu vejo ele como um professor. Aprendi muito mesmo sobre a vida, até o olhar da gente sobre o mundo, as pessoas. Parece que todo mundo fica transparente. A gente percebe mais a questão das máscaras. As máscaras das pessoas caem por terra. Eu vejo o mundo com outro olhar, valorizando cada ganho, cada aprendizado. Ele me passa muito isso, porque ele teve avanços. E pra mim o olhar dele fala, o sorriso. (Keila, 52 anos /Junho, 2020).

A cumplicidade de que trata Keila é um ponto muito importante para a reflexão. A ligação das mães com suas filhas e filhos é grande, pois eles estão sempre juntos. Um parece ser a extensão do corpo do outro. Esse é um aspecto bastante simbólico e pode significar a expressão de um grande amor, por outro lado também pode trazer angústia para mãe, filha ou filho, pois a autonomia da pessoa com paralisia cerebral, muitas vezes é limitada, e requer a constante ajuda da mãe.

As máscaras a que se refere Keila, possuem relação com a falta de solidariedade e com os preconceitos velados de muitas pessoas. Infelizmente, isso provoca nas mães, uma verdadeira batalha em que a persistência e a determinação colocariam à prova todas as adversidades do meio. (BARRETO, 2016, p. 207).

${ }^{15}$ As instâncias referem-se a saúde, transporte público, lazer, acesso a universidade, ENEM e outros.

\begin{tabular}{|l|l|l|l|l|}
\hline Qevista Dialectus & Ano 9 & n. 20 & Outubro - Novembro 2020 & p. 209-236 \\
\hline
\end{tabular}


Outro aspecto citado durante a entrevista é o da comunicação. A expressão afinada através do olhar e do sorriso é considerada por Keila como um privilégio. Essas mães aprendem outras formas de comunicação com as filhas e os filhos, visto que, alguns têm a fala comprometida pelas lesões cerebrais. Keila, de maneira semelhante à outras mães, percebeu pelo convívio com o filho David, que o importante é se fazer entender e, para isso, quando não é possível articular palavras perfeitamente, o sorriso, o choro, a expressão facial ou os movimentos do corpo, também são manifestações inteligíveis e possíveis para a efetivação de uma boa comunicação. Essa é a cumplicidade mencionada.

Além da comunicação, os corpos de mãe e filha ou filho, estão sempre muito sintonizados, pois a pessoa com paralisia cerebral necessita de auxílio constante para viver. São mulheres que, como já foi dito, banham, alimentam, conduzem, brincam, vestem, cantam, educam, o tempo todo.

Essa lida diária, também ensina as mães a enfrentar outros desafios da vida. Decerto que, algumas delas, que não contam com a ajuda de familiares, ou até mesmo, com a participação do pai de suas filhas e filhos, acabam entrando em um estado de profunda depressão. Essas mães necessitam de apoio para continuarem a enfrentar os grandes desafios cotidianos e ainda viverem suas próprias vidas enquanto mulheres.

De forma esclarecedora, Elisabeth Badinter afirma que o amor não é única motivação para as mães cumprirem com suas obrigações em relação aos filhos:

... não é só o amor que leva a mulher a cumprir seus "deveres maternais". A moral, os valores sociais, ou religiosos, podem ser incitadores tão poderosos quanto o desejo da mãe. É certo que a antiga divisão sexual do trabalho pesou muito na atribuição das funções da maternidade à mulher, e que, até ontem esta se afigurava o mais puro produto da natureza. (BADINTER, 1985, p. 17).

A despeito da responsabilidade em relação a criação dos filhos e sobre o abandono dos pais de crianças com deficiência, há informações produzidas por ONGs sobre o assunto. Em 2012, o Instituto Baresi ${ }^{16}$ realizou uma pesquisa com diferentes associações e constatou que $78 \%$ dos casais que possuem filhos com deficiência ou doenças raras, se separam devido ao abandono do pai antes que esta criança complete cinco anos de vida. Assim, todos os cuidados com a criança ficam sob a responsabilidade

\footnotetext{
${ }^{16} \mathrm{O}$ Instituto Baresi é um fórum para associações de pessoas com doenças raras, deficiências e outros grupos que tem o objetivo de melhorar a qualidade de vida e a inclusão social. O Instituto não tem fins lucrativos. O nome do Instituto Baresi é uma homenagem ao padre italiano Giampietro Baresi, missionário comboniano. https://institutobaresi.wordpress.com/author/institutobaresi/
}

\begin{tabular}{|l|l|l|l|l|}
\hline Qovista Dialectus & Ano 9 & n. 20 & Outubro - Novembro 2020 & p. 209-236 \\
\hline
\end{tabular}


da mãe, avó, ou tia. A esmagadora maioria das pessoas que assumem essas crianças, são mulheres. Nestes casos, os pais alegam não conseguirem suportar o luto da perda do "filho ideal" 17 .

Em consequência, ocorrem os danos psicológicos em todos os envolvidos, e os problemas relativos ao sustento efetivo das crianças abandonadas, ficam sob a responsabilidade das mulheres. A renda da família cai em razão das dificuldades geradas pelo aumento das despesas em função da deficiência. A questão do cuidado é um tema importante pois, efetivamente, quem cuida, também precisa ser cuidado.

Mesmo com tantas dificuldades, algumas mães conseguem elaborar estratégias de resistência diárias:

Eu costumo dizer que, o Izaque foi meu maior fisioterapeuta, porque no que eu tinha dificuldade pra me alimentar, pra me vestir, eu tive que mudar. Ele tem confiança em mim. Com outras pessoas, ele fica muito inseguro. A minha relação com ele é muito amorosa! (Edilene, 31 anos / Julho, 2020).

Vemos aqui, a fala de Edilene, mãe de Izaque, de 10 anos. Ela tem paralisia cerebral e, para cuidar de seu filho, buscou superar diversas dificuldades. Izaque que tem TDAH ${ }^{18}$ foi seu fisioterapeuta, como ela diz. Ambos construíram uma relação de confiança mútua para enfrentar os desafios e organizar uma rotina diária. Edilene também contou com a ajuda do esposo que, por sua vez, foi diagnosticado com escoliose profunda, mas que mesmo assim, sempre foi muito presente no cotidiano da família.

Sobre a expectativa de avanços em relação ao desenvolvimento das filhas e filhos, Neide, mãe de Débora, acrescenta:

\begin{abstract}
A gente mãe de pessoa com deficiência, cria uma expectativa, cria ansiedade. A gente no núcleo com a psicóloga, a gente sempre partilhava as nossas rodas de conversas e o que a gente escutava era que essa ansiedade não é bom pra gente. Muitas vezes, as mães criam expectativas do filho conseguir determinadas coisas... e muitas vezes você cria uma coisa dentro de você que não vai ter uma resposta. E o que eu coloquei em mim foi que, o que ela conseguir, tá ótimo! Estou feliz só de tentar! Tenho que dá apoio. Eu tenho o mesmo amor por ela! E aí eu comecei a ter essa visão, porque muitas vezes, isso daí pode dar até um bloqueio no próprio desenvolvimento do filho. $\mathrm{E} \mathrm{o}$ que as mães esperam e querem é aquela coisa certa. Aquela coisa perfeita. E
\end{abstract}

${ }^{17} \mathrm{O}$ Instituto Baresi organizou um "fórum para associações de pessoas com deficiências e outros grupos que congregou mães e filhos, políticos. técnicos de ONGs.https://institutobaresi.wordpress.com/author/institutobaresi/page/2/https://jornal.usp.br/atualidad es/luta-de-maes-de-criancas-autistas-e-marcada-pela-dor-do-abandono/

18 TDAH -Transtorno de Déficit de Atenção com Hiperatividade.

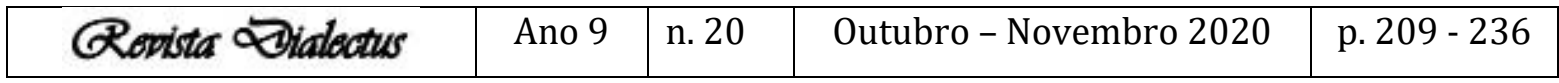


não é assim. Eu acho que a gente tem que aceitar, a gente tem que mostrar o potencial da criança, dentro do que ela conseguir. É tanto que, hoje, como experiência com a minha filha Débora, já há vinte e cinco anos, eu penso assim. Eu tenho amigas que têm criança pequena no NUTEP ${ }^{19}$, que elas têm essa visão que a gente passou. E o que a gente tem que crer é que nós temos que aceitar, que nós temos que trabalhar com o que eles podem, com o potencial deles. E a gente percebe que evolui, pelo fato do amor que a gente tem, da segurança que a gente passa. E o que for preciso a gente tá ali dando apoio, mas na hora de também falar, a gente fala o que é certo, o que é errado, pra que ele possa aprender e, aceitar também. (Neide, 47 anos / Julho, 2020).

Neide destaca, em sua narrativa, a importância da aceitação da deficiência dos filhos e ressalta que essas meninas e meninos também possuem potencial, igual a qualquer pessoa. Essa fala oferece elementos importantes para a percepção a respeito da inadequação da deficiência no imaginário de filho ideal (SOLOMON, 2013). Como se a paralisia cerebral fosse o único aspecto que caracterizasse esses indivíduos. O olhar, na grande maioria das vezes, voltado para a pessoa com deficiência é o da negatividade, do estigma, da pena ou, da ideia de superação. Essas visões, certamente, não auxiliam no processo de desenvolvimento e inclusão da pessoa com deficiência.

Em meio a esta discussão, é importante dizer que há um padrão provocador das dessemelhanças, bem descrito por David Le Breton:

Em nossas sociedade, o homem que sofre de alguma deficiência física, não é mais sentido como homem inteiro; é visto pelo prisma deformante do distanciamento ou da compaixão. Qualquer alteração notável da aparência do corpo, qualquer transtorno que afete a motricidade ou a apreensão, suscita o olhar e/ou a interrogação e até mesmo de imediato a perturbação, a estigmatização (Goffman 1975; Murphy 1990). (LE BRETON, 2013, p.86).

Retomando o trecho da entrevista de Neide, é possível afirmar que a aceitação da deficiência passa por compreender que as mães, pais e outros familiares, terão que enfrentar uma visão social essencialmente limitada da deficiência, como também ressalta Le Breton na citação supracitada. O distanciamento ou a extrema compaixão, em nada acrescentam nas vidas dos indivíduos envolvidos na questão.

Ainda sobre a mesma discussão, Ervin Goffman também esclarece:

${ }^{19}$ NUTEP - NÚCLEO DE ESTIMULAÇÃO PRECOCE. Foi fundado em 1987 e tem como objetivo implementar serviços para estimular crianças com atrasos no desenvolvimento psicomotor. Atua enquanto unidade que compõe o complexo hospitalar da Faculdade de Medicina da UFC, funcionando também enquanto campo de atividades acadêmicas para profissionais em formação da área de saúde. Além disso, possui uma oficina que oferece serviços de tecnologias assistivas voltadas para crianças com paralisia cerebral, síndrome de Down, microcefalia e outros. 
Com base nisso, fazemos vários tipos de discriminações. Através das quais efetivamente, e muitas vezes sem pensar, reduzimos suas chances de vida. Construímos uma teoria do estigma, uma ideologia para explicar a sua inferioridade, e dar conta do perigo que ela representa, racionalizando algumas vezes uma animosidade baseada em outras diferenças, tais como as de classe social. (GOFFMAN, 1988, p.15).

Diante de tantos desafios, imcompreensões, ideias de inferioridade e inadequações, as mães de pessoas com deficiência precisam de uma boa e eficiente rede de apoio para cuidarem de suas filhas e filhos com mais tranquilidade e segurança. Também necessitam de cuidados para si e o que vemos, no Brasil, é um processo histórico de exclusão e de invisibilidade dos problemas enfrentados por elas.

\footnotetext{
Outro aspecto relevante para um conhecimento maior dessas famílias é o aumento do esforço pessoal desprendido em relação as necessidades especificas de seus filhos, da dedicação e investimento objetivo e subjetivo para com cuidados físicos, estimulação precoce, revisões médicas, serviços de reabilitação, orientação psicológica, acompanhamento escolar, etc. É principalmente sobre as mães que essas responsabilidades se incidem, circunstância que pode vir a ser particularmente difícil. (LUSTOSA, 2015, p.5).
}

Geny Lustosa chama a atenção para as muitas responsabilidades e demandas que as mães possuem. Com o tempo, essas mulheres vão desenvolvendo habilidades que tem relação com a capacidade de resolução de problemas e de busca constante pelos direitos de suas filhas e filhos. Direitos estes que, mesmo sendo garantidos por lei, ainda não são respeitados pela sociedade. As lutas, muitas vezes, são enfadonhas e a única coisa que essas mães desejariam seria ajuda para continuar vivendo com dignidade e garantias.

Todos esses esforços exigem uma grande capacidade de organização da rotina dos filhos, o que, acarreta altos índices de estresse para essas mulheres.

No caso de Fortaleza, existe apoio para suas filhas e filhos, e pontualmente, para elas. São instituições que, mesmo com dificuldades estruturais, desempenham um

\begin{tabular}{|c|c|c|c|c|}
\hline Qevista Dialectus & Ano 9 & n. 20 & Outubro - Novembro 2020 & p. $209-236$ \\
\hline
\end{tabular}


bom trabalho, tais como NUTEP, IPREDE ${ }^{20}$, NAMI ${ }^{21}$ e o Hospital Sarah Kubitschek ${ }^{22}$. Infelizmente, em relação as mães, ainda é feito muito pouco. A saúde física e mental dessas mulheres que precisam carregar seus filhos nos braços, organizar uma vasta agenda de médicos e de terapias, e que, não raras vezes, foram abandonadas pelos pais de suas filhas e filhos é, verdadeiramente desumana. Fora tudo isso, ainda existem os problemas sociais de falta de escolas e creches inclusivas, transportes públicos problemáticos para cadeirantes, calçadas e locais de lazer sem acessibilidade e muito preconceito em relação a pessoa com deficiência. As mães que conseguem trabalho fora de casa, relatam uma rotina ainda mais exaustiva, pois passam pelos mesmos problemas de outras mulheres, acrescidos da rotina com suas filhas e seus filhos.

Diante de tudo isso, alguma questões são importantes: Como essas mães e mulheres se sentem? Como manter a esperança e a força para cuidar bem de suas filhas e filhos e de si próprias? Que oportunidades de trabalho essas mulheres podem ter? As respostas são dadas a cada amanhecer, quando quase sem apoio, travam a luta diária para conseguir qualidade de vida. E o preço, às vezes é, sublimar a si próprias.

O amor pelas filhas e filhos é algo construído a cada dia, mas a invisibilidade e o descaso social, político, cultural e econômico em relação a essas mães é imenso.

\title{
Ser mulher
}

\author{
A MULHER \\ Ó Mulher! Como és fraca e como és forte! \\ Como sabes ser doce e desgraçada! \\ Como sabes fingir quando em teu peito \\ A tua alma se estorce amargurada! \\ Quantas morrem saudosas duma imagem. \\ Adorada que amaram doidamente! \\ Quantas e quantas almas endoidecem \\ Enquanto a boca ri alegremente! \\ Quanta paixão e amor às vezes têm
}

${ }^{20}$ O IPREDE é uma instituição sem fins lucrativos que recebe crianças desnutridas e obesas e também oferece cursos profissionalizantes voltados às mães, com o objetivo de contribuir com a autossuficiência financeira.

${ }^{21}$ O NAMI - Núcleo de Atenção Médica Integrada da UNIFOR - Universidade de Fortaleza. A instituição oferece diversos serviços gratuitos à comunidade do entorno e restante da cidade, incluindo fisioterapia, atendimento psicológico, exames laboratoriais, terapia ocupacional e outros.

${ }^{22}$ O Sarah Kubitschek foi um hospital inaugurado em Fortaleza, no ano de 2001. A especialidade é reabilitação, mas também realiza exames, oferece orientações sobre saúde para a população, esporte, hidroterapia e orientação para familiares sobre fisioterapia e fonoaudiologia.

\begin{tabular}{|c|c|c|c|c|}
\hline Qevista Dialectus & Ano 9 & n. 20 & Outubro - Novembro 2020 & p. $209-236$ \\
\hline
\end{tabular}


Sem nunca o confessarem a ninguém

Doce alma de dor e sofrimento!

Paixão que faria a felicidade.

Dum rei; amor de sonho e de saudade,

Que se esvai e que foge num lamento!

Florbela Espanca

Verônica foi uma das participantes da pesquisa que mais me comoveu. Suas narrativas são tão fortes, quanto a poesia de Flobela Espanca. Em sua entrevista, associa perda de liberdade à maternidade. Inclusive, fala de si própria utilizando um "deslocamento", se referindo a alguém que já foi um dia, e que gostaria de resgatar. Durante a conversa, se colocou como quem se vê muito transformada pelo tempo e pela maternidade. Muitas vezes, Verônica se apresentou da seguinte forma: a Verônica tinha; a Verônica era. Sempre analisando as situações vividas apartadas do que ela é atualmente. Afirmava também o desejo de alegria e da liberdade anteriores.

Depois que eu tive ele, mudou porque eu não pude mais ter a liberdade, que a Verônica tinha. Eu não pude mais ser a Verônica por dois motivos. Por ser mãe e eu tinha que dá assistência a meu filho, porque na época o pai foi uma relação assim muito conturbada, e não tive o apoio dele na gravidez e nem no nascimento. Praticamente no quarto mês de gravidez já me senti mãe solteira. E assim eu fui levando. Quando eu engravidei eu tinha vinte anos. (Verônica, 54 anos / Junho, 2020).

Uma das questões mais relevantes e motivo de muito sofrimento para as mães de pessoas com deficiência é o sentimento de ausência de liberdade. A narrativa de Verônica nos diz abertamente que a maternidade lhe trouxe a perda de algo muito importante para ela - a sua própria autonomia. Sem ajuda do pai da criança e sem contar com uma rede de apoio necessária para enfrentar o cotidiano com mais força, Verônica diz que foi levando como pôde. Ao analisar o trecho da entrevista, podemos identificar o desamparo vivido por essa mulher que não encontrou saída e nem apoio mais imediato para resolver seus impasses pessoais , e também os problemas concretos do dia a dia.

Antes de ter ele, eu gostava de viver, de sair, de ter liberdade. Na verdade, até hoje eu vivo essa Verônica. Muitos prazeres na minha vida eu não faço com a minha família. O meu ciclo de amizades, no meu trabalho, eles sabem da minha Verônica, mas na minha casa ninguém sabe. Eu vivo essa Verônica lá, mas em casa eu tenho que ser essa Verônica mãe. (Verônica, 54 anos / Junho, 2020).

\begin{tabular}{|c|c|c|c|c|}
\hline Qovista Dialectus & Ano 9 & n. 20 & Outubro - Novembro 2020 & p. $209-236$ \\
\hline
\end{tabular}


A maternidade, para Verônia, trouxe um sentimento que a distanciou do seu ideal de liberdade e de ser mulher. Na vida pública, ou seja, no trabalho, as pessoas conhecem esse desejo e jeito livre, mas em casa, Verônica mantém a imagem de mãe, que precisa e "deve" estar totalmente dedicada a seu filho Leandro. Aqui vemos que a sociedade contribui para a cisão - mulher e mãe, a ponto das mulheres se verem tendo que optar por ser uma das duas. Optar por se ver e se sentir mulher, pode parece para muitos, algo indigno e até egoísta.

A histórica separação entre as concepções de ser mulher e ser mãe, possui uma conotação também religiosa, visto que, há tempos e em diferentes culturas mundiais, as duas faces não encontram "permissão" moral para coexistirem numa mesma pessoa. A lógica binária do bem e do mal, do feminino ou do masculino, do normal ou anormal, da mãe ou da mulher, exemplificam esse problema.

Durante a entrevista, imaginei quantas mulheres na mesma situação não têm espaço e nem coragem para relatar que maternidade também é algo que as faz sofrer, principalmente quando a filha ou o filho não corresponde ao imaginário social ideal.

É sonhar alto. É querer realizar sonhos que eu deixei pra trás. Eu tive pensamento, eu tive vontade, mas não consegui realizar, pelas minhas falhas, pelos meus erros, pela minha teimosia. Por não ter ouvido meus pais na época. Pelo juízo doido. Fiz muita coisa errada na minha vida. Fiz, fiz. Coisas que eu me arrependi. Coisas que eu não me arrependi. Mas coisas do passado que eu não posso voltar atrás. Você tem que pensar no hoje. Na época eu vivia tudo isso. Eu vivia passado, presente e futuro. Eu queria abarcar o mundo com as mãos. E quebrei muito a minha cara! A gente não pode mudar o passado. A única coisa boa que ficou do passado que eu tô tentando resgatar é a Verônica de 30 anos atrás. Essa Verônica. Mesmo com meu filho com deficiência, mesmo com preconceito, mesmo com a minha idade, eu quero ter essa Verônica. (Verônica, 54 anos / Junho, 2020).

A narrativa supracitada nos traz um balanço de vida, em que supostos erros, sonhos e desejos são colocados em reflexão. A culpa está fortemente presente. E a responsabilidade de ter um filho com deficiência tornou-se algo, por vezes, pesado. Para Verônica, o resgate da alegria de quem ela era há 30 anos é algo importante. Ela afirma que "mesmo" com a luta contra o preconceito e com os cuidados que precisa ter com Leandro, deseja que sua vida mude. Verônica também traz o etarismo ${ }^{23}$, por ser uma mulher de 54 anos e sentir o preconceito existente.

${ }^{23}$ Etarismo é o preconceito em relação a faixa etária de uma pessoa ou grupo - os idosos no caso aqui. Diz respeito a estigmas relacionados a saúde, beleza, desempenho, capacidade intelectual, memória e outros.

\begin{tabular}{|c|c|c|c|c|}
\hline Qevista Dialectus & Ano 9 & n. 20 & Outubro - Novembro 2020 & p. $209-236$ \\
\hline
\end{tabular}


Em uma perspectiva diferente de Verônica, Edilene apresenta um outro olhar sobre toda essa problemática da vivência do feminino e da deficiência.

Eu acho que eu consigo separar porque a mãe deve tá viva, mas eu sempre procuro tirar um tempo pra mim. Eu vou à praia todo mês, ou saio com as meninas, ou vou ao salão de beleza. Um dia pra me permitir. Nós precisamos disso! (Edilene, 31 anos / Julho, 2020).

Edilene que é a única entrevistada que tem paralisia cerebral, não avalia sua condição em nenhum momento, como sendo algo que a impede de ter uma vida em que também existem o autocuidado, o lazer, a alegria e o descanso. Com uma fala bastante positiva, quando diz nós precisamos disso, está se referindo ao fato de ser mãe como qualquer outra mulher. Edilene encontrou seu jeito de encarar a vida com naturalidade, sem maiores queixas. Ela se cuida, cuida do filho, da casa e ainda participa de atividades a convite de instituições que desejam ouvir sobre sua experiência positiva.

Interessante observar o ponto de vista de Keila também, quando perguntei sobre a sua condição de mulher em meio a tantos desafios diários:

Como mulher mesmo eu acho que me anulo. Me anulo até porque quatro homens nessa solicitação, então eu acho que me anulo muito como mulher! Eu sou muito cobrada em relação a isso. Até na família mesmo. É sou. (Keila, 52 anos / Junho, 2020).

Keila afirma que se sente cobrada e relaciona o fato de ser mulher unicamente à vaidade e não a seus sentimentos, desejos, sonhos e outras dimensões da vida. Diz que é muito solicitada por quatro homens, afirmando o lugar social daquela que cuida, e que é muito exigida.

O ideal, eu sustentava, também servia a um fim político. Quanto mais fortes as mulheres se tornassem em termos políticos, maior seria o peso do ideal de beleza sobre seus ombros, principalmente para desviar e solapar seu desenvolvimento. (WOLF, 2020, p. 16).

Naomi Wolf chama a atenção para as exigências sociais em torno do padrão de beleza. No mundo social, a mulher não pode se desviar de sua tarefa principal que é se manter bela. O envolvimento político, segundo sua argumentação, enfraquece esse objetivo que é visto como existencial. Esta imposição também cultural é, no mínimo, cansativa para mulheres que se desdobram em mil, para conseguir dar conta das diversas

\begin{tabular}{|l|l|l|l|l|}
\hline Govista Qialectus & Ano 9 & n. 20 & Outubro - Novembro 2020 & p. 209 - 236 \\
\hline
\end{tabular}


demandas existentes em suas vidas. Em sociedades patriarcais, extremamente desiguais e machistas, a beleza é cobrada pelos homens com o peso do poder que foram "autorizados" socialmente a ter.

Diante de tantas vértices, fica difícil, para Keila, ainda conseguir um tempo unicamente para si, pois as demandas dos movimentos sociais também somam no seu cotidiano. Mesmo tendo uma visão ampliada a respeito dos direitos de seu filho David, parece não se preocupar com seus próprios direitos, ou seja, direito a lazer, a divisão de tarefas em casa, e outros.

As mulheres brasileiras são criadas para servir, cuidar, e essa é uma mentalidade difícil de mudar. Cansam-se muitas vezes de tentar lutar contra o que está posto antes mesmo delas nascerem, pois assim foi com as outras mulheres de sua família, salvo raras exceções. E quando demonstram seu incômodo, os conflitos familiares acontecem.

Sobre esse assunto, Neide também contribui:

Eu como mulher, mudou muito assim, a questão, a minha responsabilidade como mãe, mulher e, o que mudou pra mim também, foi renunciar, eu tive que renunciara muitas coisas na minha vida. Meus pais passaram muitos anos casados e eles se separaram. E dessa separação eu tive que ficar trabalhando. Desde nova que trabalhei. Eu era de menor, estudava e trabalhava. E aí quando eu tive a Débora, eu tive que renunciar, porque eu tinha tá no tratamento da minha filha. E também, eu acho devido algumas situações, tipo da gravidez que eu passei, eu cheguei algumas vezes a me sentir um pouco culpada. Que até então o meu esposo achou que pelo fato da Débora ter nascido com paralisia cerebral, devia ter sido algo relacionado a mim como mãe, mas aí eu conversando com a doutora ela disse que de jeito nenhum. Isso é uma coisa que acontece. (Neide, 47 anos /Julho, 2020).

Foi difícil para Neide falar de sua condição de mulher de maneira dissociada da condição de mãe. Talvez pelo fato de ter renunciado a si própria para trabalhar e estudar desde cedo. Quando Débora nasceu, passou a se dedicar quase que integralmente, aos cuidados com a filha. A culpa de que fala Neide é algo recorrente nos relatos de mães de pessoas com paralisia cerebral. Elas ficam procurando motivos em si para justificar o acontecimento da paralisia. A própria família, os pais por exemplo, muitas vezes, as culpam, caracterizando, assim, uma situação de violência simbólica.

Porque naquela época não tinha atividade na saúde. Eu cheguei a ir pra maternidade na época. Eu ia e voltava. Passei por todas essas situações. A bolsa se rompeu. E eu conversando com Deus e com a doutora, e com tudo isso a minha filha com as dificuldades dela, ó senhor! Mas eu vou tentar ajudar. O que for preciso eu renunciar a minha vida. Fiz tratamento com ela, muitas vezes, eu como mãe e mulher, eu me sentia sobrecarregada porque tanto era 
pra fazer as coisas de casa, como era pra tá no tratamento com a minha filha, como era pra dá atenção pro esposo. Isso também fez com que eu crescesse mais na minha vida né, porque a gente ficava com outras mães, a gente partilhava, cada uma tem uma história de vida. Então, isso me fortaleceu e me fez crescer também né, mas que pra gente mãe com filha ou filho com deficiência, renunciamos muito a nossa vida! Eu passei muitos anos até mesmo pra ter outra filha. As pessoas diziam assim: você tem coragem de ter outra filha? Eu dizia: tenho sim e por que não! (Neide, 47 anos / Julho, 2020).

Novamente a questão da renúncia aparece em sua narrativa, pois a sobrecarga de trabalho é colocada como motivo para cuidar menos de si. Outro aspecto que se faz muito presente nas vidas dessas mulheres é a curiosidade de pessoas a respeito de questões intimas. Neide traz essa questão em sua narrativa, situando também a resposta enfática à pessoa que perguntou. A própria pergunta parece já atribuir um peso à vida de Neide. Perguntas constrangedoras são uma constante nas vidas dessas mulheres, tais como: O que aconteceu com ele? Ele nasceu assim? Ele entende o que a gente fala? Por que ele não anda? Por que ele não fala? Você tem outros filhos?

Sobre o assunto, Andrew Solomon contribui:

Esses pais também sofrem mudanças profundas causadas por suas experiências. Se você tem um filho com deficiência, será para sempre o pai de um filho com deficiência; é um dos fatos básicos a seu respeito, fundamental para a maioria como as outras pessoas o percebem e decifram. (SOLOMON, 2013, p. 17).

Diante de tantos desafios, cuidar delas mesmas, ou seja, da sua condição de mulher é no mínimo, desafiador. Chega a ser um ato de "teimosia", até mesmo, de rebeldia diante de uma sociedade tão preconceituosa e dos problemas estruturais e políticos existentes no Brasil.

Devo dizer que Keila, Verônica, Edilene e Neide, cada uma a sua maneira, encaram a vida com suas filhas e filhos, ultrapassando os próprios limites. São todas mulheres que escolheram lutar pelos direitos da pessoa com deficiência e contra a ignorância. Além disto, não aceitaram a invisibilidade histórica que camufla e atenua, a falta de apoio do poder público para com elas e suas filhas e filhos. Tudo que conquistaram foi à custa de suas próprias iniciativas, e das parcerias sensíveis que foram encontrando ao longo de suas trajetórias de vida.

Em relação as percepções sobre a condição de mulher, sem dúvida há uma visão muito relacionada a manutenção da beleza física. Essa perspectiva é um reflexo das exigências de padrões culturais construídos por uma sociedade patriarcal e machista. Suas

\begin{tabular}{|c|c|c|c|c|}
\hline Qevista Dialectus & Ano 9 & n. 20 & Outubro - Novembro 2020 & p. $209-236$ \\
\hline
\end{tabular}


condições de mulher aparecem em suas narrativas sem ligação às suas construções intimas, desejos, sonhos e realizações individuais.

\section{Considerações Finais}

A escrita deste texto significou muito mais do que o esforço de sistematizar ideias e dados para a reflexão sobre um tema. Neste espaço, pude ter um "encontro" sincero e forte com mulheres que vivem, resistem, criam, recriam e sofrem todos os dias na tentativa de construir um mundo melhor para suas filhas e filhos. Semelhantes e também diferentes ao mesmo tempo, essas mães e mulheres veem a necessidade urgente de justiça, acessibilidade, educação, saúde e lazer. A convivência com suas filhas e filhos, proporcionou olhares mais críticos em relação a necessidade de mudança de maneiras de pensar e de agir em relação a deficiência.

Divulgar a felicidade aprendida por esses pais é vital para sustentar identidades que hoje estão vulneráveis à erradicação. Suas histórias apontam para todos nós um caminho para expandir nossas definições de família humana. (SOLOMON, 2013, p. 17).

A felicidade para as participantes da pesquisa, nasceu das conquistas e das lutas travadas. É imprescindível que haja mais apoio para todas as mulheres que buscam uma vida digna para suas filhas e filhos. E que elas próprias não tenham que se sentir tão sozinhas diante do abandono, dos preconceitos, da violência, das ausências, da curiosidade indiscreta, do medo do futuro e do cansaço, fruto do trabalho excessivo. Precisam se cuidar e precisam ser cuidadas! São pessoas muito importantes para suas famílias e para a sociedade. São detentoras de conhecimentos que podem expandir realmente as definições de família e de vida, como lembra Solomon.

Faz-se necessária a constituição de redes de apoio para as mães se estruturarem e se organizarem melhor. Uma sociedade justa sempre se preocupa com o bem-estar das mulheres. E quando tratam-se de vidas que dependem delas para serem “incluídas", é imprescindível o apoio do poder público, da família, das escolas, dos profissionais da saúde e das comunidades em que vivem.

Do contrário, não poderemos sustentar nenhum ideal de sociedade justa, visto que a deficiência tem sido motivo de dor para muitas mulheres, mesmo que também seja

\begin{tabular}{|l|l|l|l|l|}
\hline Govista Qialectus & Ano 9 & n. 20 & Outubro - Novembro 2020 & p. 209-236 \\
\hline
\end{tabular}


motivo de alegria e de aprendizado. É chegada a hora de entender as diferenças como uma face importante da vida!

\section{Referências}

AMARAL, L.A. Conhecendo a deficiência (em companhia de Hercules). São Paulo: Robia, 1995.

BADINTER, E. Um amor conquistado: o mito do amor materno. Tradução Waltensir Dutra. Rio de Janeiro: Nova Fronteira, 1985.

BARRETO, E. O corpo rebelado: autonomia, cuidado e deficiência física. $1^{\mathrm{a}}$ ed. Curitiba, Appris, 2016.

CHAGAS, E. F. A Vontade é Livre? Natureza e Ética em Ludwig Feuerbach. Revista Dialectus , v. 3, p. 1, 2015.

DELEUZE, G. Lógica do Sentido. (4ª ed.). São Paulo: Perspectiva, 2000.

ESTÉS, C.P. Mulheres que correm com os lobos: mitos e histórias do arquétipo da mulher selvagem. Tradução Waldéa Barcellos. Rio de Janeiro: Rocco, 1994.

GOFFMAN, E. Estigma. Notas sobre a manipulação da identidade deteriorada. Tradução: Marcia Bandeira de Mello Leite Nunes. Rio de Janeiro: Editora Guanabara S.A, 1988.

LE BRETON, D. Adeus ao corpo: antropologia e sociedade. Campinas: Papirus, 2013.

LOURO, G.L. (Org.) O corpo educado. Pedagogias da sexualidade. Belo Horizonte: Autêntica Editora, 2019.

. Gênero, sexualidade e educação: uma perspectiva pós-estruturalista. Petrópolis, RJ: Vozes, 2014.

LUSTOSA, F.G. Inclusão, o olhar que ensina: o movimento da mudança e a transformação das práticas pedagógicas no contexto de uma pesquisa-ação colaborativa. Fortaleza: UFC, 2009, 295 f. Tese de Doutorado apresentada ao Programa de PósGraduação em Educação da Universidade Federal do Ceará, Fortaleza, 2009.

. Mães da Inclusão: trajetórias de amor e luta na defesa dos direitos dos filhos. IN: CAVALCANTE, M.J.M; HOLANDA, P.H.C; QUEIROZ, Z.F.(Org.). Histórias de mulheres: amor, violência e educação. 1ed. Fortaleza: Edições UFC, 2015, v1, p. 177195.

\begin{tabular}{|l|l|l|l|l|}
\hline Govista Dialectus & Ano 9 & n. 20 & Outubro - Novembro 2020 & p. 209 - 236 \\
\hline
\end{tabular}


MANTOAN, M. T. E. O direito de ser, sendo diferente, na escola. Revista CEJ, Brasília, n. 26, p. 36-44, 2004.

Inclusão escolar: o que é? por quê? como fazer? São Paulo: Moderna, 2003. (Coleção cotidiano escolar).

O direito a diferença nas escolas. Pátio - Revista Pedagógica, Porto Alegre, v. 8, n. 32 , p. $12-15,2004$.

. Igualdade e diferenças na escola como andar no fio da navalha. Educação (PUC/RS), Porto Alegre / RS, v. XXIX, n. 1 (58), p. 55-64, 2006.

SILVA, T.T DA.(Org.). Identidade e diferença: a perspectiva dos estudos culturais. $15^{\text {a }}$ Ed. Petrópolis, RJ: Vozes, 2014.

SOLOMON, A. Longe da árvore: pais, filhos e a busca da identidade. Tradução Donaldson M. Garschagen. $1^{a}$ ed. São Paulo: Companhia das Letras, 2013.

TERRASSI, E. Família do deficiente: aspectos comuns e específicos contidos no relato de mães de crianças portadoras de diferentes deficiências. 1993. 98 f. Dissertação (Mestrado em Educação Especial) - Centro de Educação e Ciências Humanas, Universidade Federal de São Carlos, São Carlos - SP ,1993.

WOLF, N. O mito da beleza: como as imagens da beleza são usadas contra as mulheres. Tradução - Waldéa Barcellos - 11 $1^{\mathrm{a}}$ ed. Rio de Janeiro: Rosa dos Tempos, 2020. 